\title{
Aus unserer Bildermappe
}

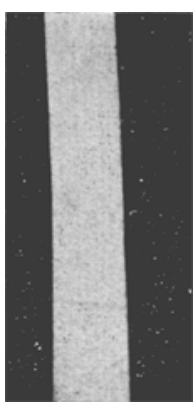

Abb. 1.

Ohne weitere Behandlung, Breite $5 \mathrm{~cm}$.

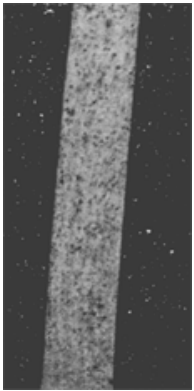

Abb. 2 .

Nach Bearbeitung mit dem Staubsauger.

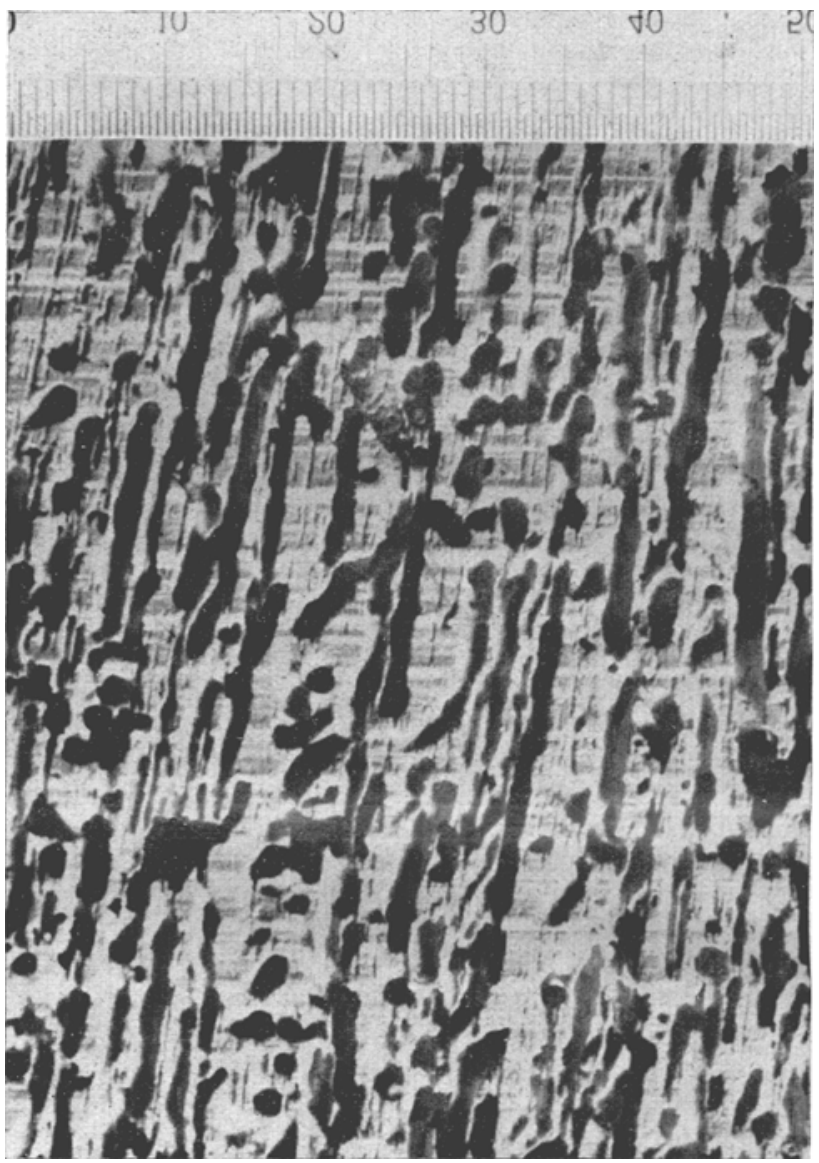

Abb. 3.

Dieselbe in starker Vergrößerung.

Der Fraß von Lyctus linearis Goeze in Nußbaumbolz. Das Holz ist der Länge nach durch einen Sägeschnitt gespalten. Die schwarzen Pünktchen zeigen die Bohrlöcher. Bilder: Eckstein.

\section{Mitteilungen der Deutschen Gesellschaft für angew. Entomologie E.V.}

Prof. Dr. H. Eidmann erhielt eine Einladung zum Studium des Problems der Bekämpfung der Blattschneiderameisen in Brasilien. Die Blattschneiderameiseu gehören bekanntlich zu den wichtigsten land- und forstwirtschaftlichen Schädlingen des neotropischen Gebietes. lhre Bekämpfung ist trotz zahlreicher diesbezüglicher Arbeiten in einer allgemein brauchbaren und wirtschaftlichen Weise noch nicht möglich. Prof. Eidmann ist am 12. August von Hamburg aus nach Brasilien abgereist und wird Ende dieses Jahres wieder zurückkehren.
Dr. Johannes Wille (aus Gera Thür.). der ChefEntomologe von Peru und Leiter der Entomologischen Abteilung der Estacion experimental Agricola wurde zum. "Jefe y Profesor" für Entomologie an der neu geschaffenen Landwirtschaftlichen Hochschule für Peru (Instituto de Altos Estudios Agricolas del Pern) ernannt. Prof. Dr. Wille hält von jetzt ab Vorlesungen über allgemeine und angewandte Entomologie. Diese Ernennung ist ein erneuter Beweis für die erfolgreiche Tätigkeit Willes in Peru auf entomologischem Gebiete. 